\title{
The world of analytics: interdisciplinary, inclusive, insightful, and influential
}

\author{
Anjala S. Krishen ${ }^{1} \cdot$ Maria Petrescu $^{2}$
}

Published online: 18 April 2017

(C) Macmillan Publishers Ltd 2017

As we searched for ways to deliver our first editorial, we decided to learn from our experiences as researchers. After all, we seek to discover new ideas and create new pathways from which to enhance the journal, so why not begin with a qualitative exploration? We chose to combine the purpose of the journal itself with the idea of stepping back to explore the term "analytics"; from this, we decided to utilize semantic analysis.

\section{Exploratory study}

The goal of the study is to gather qualitative information regarding the concepts and themes involved in and around marketing analytics. To do this, we chose to use an adapted version of netnography as our methodology, a technique which involves the study of online communities or material (Kozinets 2002).

\section{Procedure and analysis}

As a first step in understanding the issues, conversations, and ideas surrounding marketing analytics, we began with a multiple-phase netnographic analysis. In the first phase, in March of 2017, two trained graduate students who were

Anjala S. Krishen

anjala.krishen@unlv.edu

Maria Petrescu

mpetresc@nova.edu

1 Department of Marketing and International Business, University of Nevada, 4505 Maryland Parkway, Las Vegas, NV 89154, USA

2 Nova Southeastern University, Fort Lauderdale, USA unaware of the purpose of this research were tasked with gathering data about the term "marketing analytics." Based on the literature, the students followed these instructions: (1) use the four terms: marketing analytics, business analytics, decision analytics, and process analytics; (2) For each term, perform a Google.com search; and (3) For each of the first few pages of search results, open each website link, identify the place where a definition for the term exists, and store it in a spreadsheet. This process led to $N=64$ definitions, with $n=18$ for "marketing analytics," $n=17$ for "business analytics," $n=15$ for "decision analytics," and $n=14$ for "process analytics." We chose an unguided semantic analysis tool called Leximancer to explore themes from these definitions. Leximancer (www.leximancer.com) determines themes and their underlying concepts (subthemes) from qualitative data (Smith 2011) using a machine learning technique. Many existing research studies from various disciplines contain analysis performed by this tool, which is based on Bayesian theory (e.g., Campbell et al. 2011; Dann 2010; Kirkendall and Krishen 2015; Krishen et al. 2016). The tool also provides comparative diagrams derived from multiple files, such as comparing these four different search term definitions and calculating relative weights of themes and concepts from them (Rooney 2005).

\section{Results}

Analysis of the data consists of semantically characterizing each of the definitions of the search terms followed by a comparison of the aggregate results from each term and its interrelationship with the aggregate results from the other terms. Figure 1 provides a set of themes and their interrelationship, mapped with respect to the four search terms, 
Fig. 1 Analytics themes and concepts

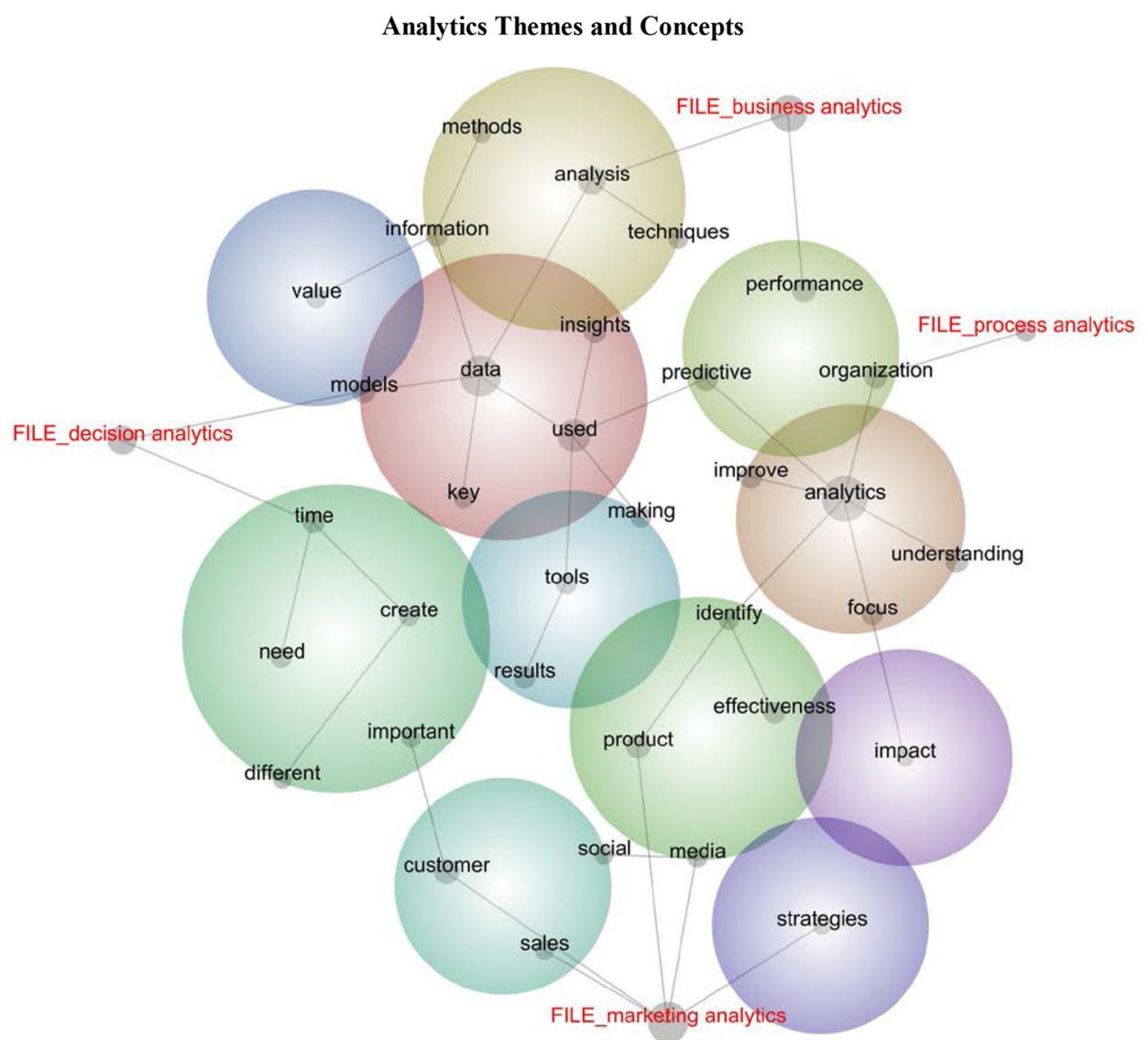

shown as FILE_marketing analytics, FILE_business analytics, FILE_decision analytics, and FILE_process analytics. To define all four of the terms as a complete aggregate, as shown in Fig. 1 with large circles and provided in the left-hand column of Table 1, the outcome themes include data, analytics, analysis, predictive, product, time, customer, results, value, strategies, and impact.

\section{Discussion}

Sample definitions for each of the themes and the concepts within them are provided in Table 1. The themes are ordered from the most prominent (or most frequent) to the least frequent in the table. Alongside this Table, Fig. 1 shows the concepts within the themes and highlights the prominence of the concepts by various sizes of gray circles within each of the themes, which are represented by the larger circles. The eleven larger circles represent the themes, and the concepts are overlaid within them on top of smaller gray circles. These themes are connected to each other to represent the frequency of representation of the concepts with each other. The analysis also provides relational information about the concepts across the four different search terms (marketing, business, decision, and process analytics). The direct concept connections from marketing analytics include sales, customer, product, media, and strategies; from business analytics include analysis and performance; from decision analytics include models, and time; and from process analytics include organization. The terms connected directly to the analytics concept include organization, predictive, improve, identify, focus, and understanding. These ideas center on gaining an understanding and then identifying and focusing in an organized manner to provide a predictive solution.

\section{Conclusion}

Using our data-driven process to explore various definitions of analytics, we present Fig. 2 which proposes our conceptualization. In the center of the diagram are the four key terms that were searched and the outcome themes directly connected to them. For business analytics-analysis and predictive were the main themes, for process analytics-predictive, for decision analytics-data and time, and for marketing analytics-customer, product, and strategies. Thus, we view analytics as an interdisciplinary and inclusive area of study which aims to be insightful and ultimately enable timely and influential firm-driven 
Table 1 Analytics sample definitions $(n=64)$

\begin{tabular}{|c|c|c|}
\hline Theme & Key concept & Sample definitions \\
\hline \multirow[t]{5}{*}{ Data } & Data & Variety of data \\
\hline & Used & Can be defined as a broad use of data \\
\hline & Models & $\begin{array}{l}\text { While Business Intelligence answers what happened, Business Analytics answers why it happened and whether it } \\
\text { will happen again. Business Intelligence includes reporting, automated monitoring and alerting, dashboards, } \\
\text { scorecards, and ad hoc query; Business Analytics, in contrast, includes statistical and quantitative analysis, data } \\
\text { mining, predictive modeling, and multivariate testing }\end{array}$ \\
\hline & Insights & Blend any data with a click, then share insights as a visual story. It enables you to outperform your peer groups \\
\hline & Key & $\begin{array}{l}\text { What kind of data you'd need to answer your critical question and decide how to measure it. With your question } \\
\text { clearly defined and your measurement priorities set, now it's time to collect your data }\end{array}$ \\
\hline \multirow[t]{4}{*}{ Analytics } & Analytics & Business Analytics is a complete solution for connecting and collaborating with analytics in the cloud \\
\hline & Understanding & $\begin{array}{l}\text { The intuitiveness and transparency of the decision analytic process ensures major stakeholders, analytic teams, and } \\
\text { decision makers possess a deepened understanding of the decision problem and the confidence to act on the } \\
\text { strategic directives indicated }\end{array}$ \\
\hline & Improve & Make decisions, improve processes \\
\hline & Focus & Analytics are focused \\
\hline \multirow[t]{4}{*}{ Analysis } & Analysis & $\begin{array}{l}\text { Different specializations exist, encompassing most significant aspects of business, including risk analysis, market } \\
\text { analysis, and supply chain analysis }\end{array}$ \\
\hline & Information & $\begin{array}{l}\text { Analytics is a field which combines data, information technology, statistical analysis, quantitative methods and } \\
\text { computer-based models into one. This all are combined to provide decision makers all the possible scenarios to } \\
\text { make a well thought and researched decision }\end{array}$ \\
\hline & Techniques & $\begin{array}{l}\text { Business process analysis techniques including process discovery and visualization, conformance checking and } \\
\text { delta analysis, and rule-based checking }\end{array}$ \\
\hline & Methods & $\begin{array}{l}\text { Process analytics is the method of measuring and monitoring a wide array of systems and components. This } \\
\text { analysis is essential for environmental compliance and sustainable plant production in a wide variety of industries } \\
\text { around the world }\end{array}$ \\
\hline \multirow[t]{3}{*}{ Predictive } & Predictive & To understand and predict \\
\hline & Performance & It is used for predictive analysis, which is typically used to assess previous business performance \\
\hline & Organization & $\begin{array}{l}\text { That proprietary, cloud-based platform to improve marketing strategies through predictive analytics, data } \\
\text { management, and visualization }\end{array}$ \\
\hline \multirow[t]{4}{*}{ Product } & Product & Development and new venture launching \\
\hline & Effectiveness & $\begin{array}{l}\text { Then offer improvements or upgrades on existing products or services a customer has already purchased (up- } \\
\text { selling). Customer segmentation analytics improve the effectiveness of marketing campaigns and decrease costs } \\
\text { by grouping customers into segments based on specific attributes, and then predicting which segments are most } \\
\text { likely to purchase a particular product or service }\end{array}$ \\
\hline & Identify & $\begin{array}{l}\text { By identifying who is not buying from you (and why), you can expand your market to include those individuals. If } \\
\text { you want to know why people are not buying your product or service, you need to ask them: interviews, } \\
\text { questionnaires and focus groups can help }\end{array}$ \\
\hline & Media & $\begin{array}{l}\text { You can source this sort of data anywhere your customers and potential customers are discussing your brand, such } \\
\text { as customer service conversations, sales conversations, online forums, blogs, review sites, and social media. }\end{array}$ \\
\hline \multirow[t]{3}{*}{ Time } & Time & Delivering the right decision support to the right people at the right time \\
\hline & Need & $\begin{array}{l}\text { What technology is used to help provide the business need. This obviously does change over time - sometimes } \\
\text { radically }\end{array}$ \\
\hline & Create & $\begin{array}{l}\text { In order to create an accurate picture of the quality of current marketing efforts. Marketing Mix Modeling (MMM) } \\
\text { demonstrates how each unique marketing touch, as well as non-marketing variables, impact sales volume }\end{array}$ \\
\hline \multirow[t]{2}{*}{ Customer } & Customer & Is this customer about to leave us for a competitor? \\
\hline & Social & It can be remarkably easy to get feedback from people who are not your customers using the power of social media \\
\hline \multirow[t]{2}{*}{ Results } & Tools & Google Analytics is used by 55 percent of all websites and has a traffic analysis tool market share of 83 percent. \\
\hline & Making & $\begin{array}{l}\text { This is called data driven decision making. Making decisions based on data allows businesses to operate more } \\
\text { efficiently, and the more data based decisions they make with positive results, the more they can simplify the } \\
\text { process by coming up with formulas for the future }\end{array}$ \\
\hline Value & Value & To fully support data-driven marketing \\
\hline Strategies & Strategies & $\begin{array}{l}\text { "Content" is a tactic, not a strategy. "Content" is produced in the execution of strategies such as advertising, SEO } \\
\text { and publicity }\end{array}$ \\
\hline Impact & Impact & $\begin{array}{l}\text { Commitment and successful strategic planning. However, it's often "where the rubber hits the road" that the } \\
\text { greatest impact can occur }\end{array}$ \\
\hline
\end{tabular}




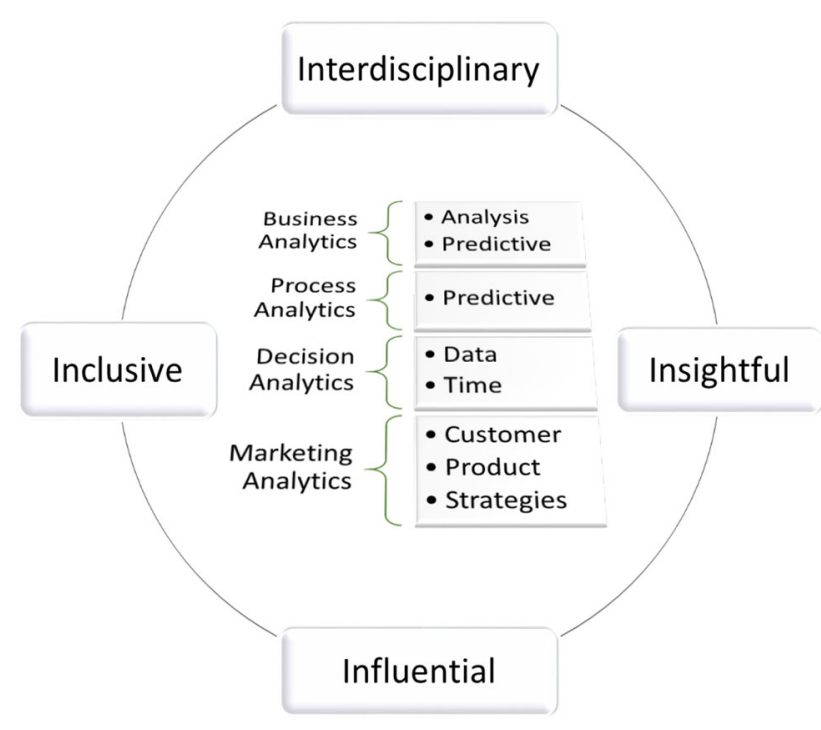

Fig. 2 Conceptual view of marketing analytics

campaigns. In this vein, we welcome contributions from multiple disciplines of scholarly discourse as well as timely practitioner insights and ideas to the Journal of Marketing Analytics.

Acknowledgements The authors thank graduate students Kyle Styck and Trupti Jadav, the University of Nevada, Las Vegas for help with data collection, and Eduardo Robleto, the University of Nevada, Las Vegas for reading and providing comments.

\section{References}

Campbell, C., L.F. Pitt, M. Parent, and P.R. Berthon. 2011. Understanding consumer conversations around ads in a Web 2.0 world. Journal of Advertising 40(1): 87-102.

Dann, S. 2010. Redefining social marketing with contemporary commercial marketing definitions. Journal of Business Research 63(2): 147-153.

Kirkendall, A., and A.S. Krishen. 2015. Encouraging creativity in the social work classroom: insights from a qualitative exploration. Social Work Education 34(3): 341-354.

Kozinets, R.V. 2002. The field behind the screen: Using netnography for marketing research in online communities. JMR, Journal of Marketing Research 39(1): 61-72.

Krishen, A.S., S. Agarwal, and P. Kachroo. 2016. Is having accurate knowledge necessary for implementing safe practices? A consumer folk theories-of-mind perspective on the impact of price. European Journal of Marketing 50(5-6): 1073-1093.

Rooney, D. 2005. Knowledge, economy, technology and society: the politics of discourse. Telematics and Informatics 22(4): 405-422.

Smith, A. (2011). Leximancer Manual (Version 4) [Electronic Version]: from https://www.leximancer.com/wiki/images/7/77/ Leximancer_V2_Manual.pdf. 